\title{
La cercanía-lejanía entre pensar y poetizar en Martin Heidegger
}

Orlando Ortega Chacón

Universidad Nacional de Colombia 


\title{
La cercanía-lejanía entre pensar y poetizar en Martin Heidegger*
}

Resumen: en las obras tardías de Martin Heidegger puede advertirse una dificultad de distinción entre dos aspectos fundamentales de su pensamiento: pensar y poetizar. No resultan muy claras las distinciones que el mismo filósofo establece, por ejemplo: "así y todo, no podemos decidir aquí de manera definitiva si la poesía es, en lo propio, una forma de pensamiento o si el pensamiento es, en lo propio, una forma de poesía" (Heidegger, 2002, p. 140). Es bastante «oscura» la relación entre estos dos modos del decir, más aún cuando el mismo filósofo alemán deja en claro que estos dos «vecinos» se encuentran bajo una «luminosa» diferencia. Por ello, surge la pregunta: ¿qué tan clara tiene el mismo Heidegger la diferencia entre pensar y poetizar cuando reconoce una «oscuridad» en la relación, pero afirma una «luminosidad» en la diferencia?

Palabras clave: pensar, poetizar, decir, vecindad, escucha, silenciamiento.

\section{The closeness-distance between thinking and poetizing in Martin Heidegger}

\begin{abstract}
Martin Heidegger's later works, one can notice a difficulty in distinguishing between two fundamental aspects of his thought: thinking and poetizing. The distinctions that the philosopher himself establishes are not very clear, for example: "even so, we cannot decide here definitively if poetry is, in itself, a form of thought or if thought is, in itself, a form of poetry" (Heidegger, 2002, p. 140). The relationship between these two modes of saying is quite «dark», even more so when the same German philosopher makes it clear that these two «neighbors» are under a «luminous» difference. Therefore, the question arises: how clear is Heidegger himself the difference between thinking and poetizing when he recognizes a «darkness» in the relationship, but affirms a «luminosity» in the difference?
\end{abstract}

Keywords: think, poetize, saying, neighbourhood, listening, silencing.

Fecha de recepción: 17 de agosto de 2019

Fecha de aceptación: 25 de febrero de 2020

Forma de citar (APA): Ortega-Chacón, O. (2020). La cercanía-lejanía entre pensar y poetizar en Martin Heidegger. Revista Filosofía UIS 19(2), https://doi.org/10.18273/revfil.v19n2-2020006

Forma de citar (Harvard): Ortega-Chacón, O. (2020). La cercanía-lejanía entre pensar y poetizar en Martin Heidegger. Revista Filosofía UIS 19(2), 99-112.

Orlando Ortega Chacón: colombiano. Magíster en Filosofía Contemporánea de la Universidad San Buenaventura. Profesor Universidad Nacional de Colombia.

ORCID iD: orcid.org/0000-0002-9660-6829

Correo electrónico: oortegac@unal.edu.co,orlando.ortega.chacon@gmail.com

*Artículo de reflexión derivado de investigación.

Revista Filosofía UIS, vol. 19 n. ${ }^{\circ}$ 2, julio - diciembre 2020 


\section{La cercanía-lejanía entre pensar y poetizar en Martin Heidegger}

"Lo hablado del poema es lo que el poema exterioriza desde sí mismo en el decir"

(Heidegger, 2002, p. 14)

\section{Introducción}

«Pensar»y «poetizar» son dos términos de una relevancia considerable para comprender la obra tardía ${ }^{1}$ de Martin Heidegger. Así, sobresalen textos como Aclaraciones a la poesía de Hölderlin, escritas entre 1936-1969, las lecciones de 1951-1952 tituladas ¿Qué significa pensar? Y los artículos escritos entre 19501959 (publicados en De camino al habla), entre otros. En estos textos sucede que los términos («pensar» y «poetizar») son utilizados polisémicamente y por ello se agrava la posibilidad de interpretar de forma correcta lo que el autor está diciendo en cada caso. De este modo, aunque la acepción ordinaria de «pensamiento» — relacionada tradicionalmente con el proceder calculador de la ciencia- y «poesía» — vinculada con el pensamiento meditativo—nos sugiere diferencias de estilo y contenido en cada caso; en la obra del filósofo alemán estas difuminan sus fronteras y hacen difícil una lectura que las diferencie. Por esta razón es necesario un ejercicio de hermenéutica que esclarezca si en las obras posteriores a 1930 estos dos términos presentan o no fronteras despejadas.

\footnotetext{
1 Adopto la distinción que elabora Arturo Leyte entre la parte escrita de Ser y tiempo y la parte proyectada del mismo. Es bastante conocido el hecho de que el libro de 1927 del filósofo de Friburgo no se terminó de escribir. En efecto, la parte no escrita de Ser y tiempo es entendida por Leyte como el proyecto inacabado de la tarea de pensar el ser desde la destrucción de la ontología tradicional. Veamos el comentario que hace el especialista en Heidegger: "el carácter de «inacabado» sugiere un «defecto», cuando en realidad puede resultar una cualidad intrínseca a la cuestión de que se trata: porque inacabado puede expresar la naturaleza misma de un trabajo filosófico cuando no puede aparecer como «doctrina». En realidad, Ser y tiempo es la expresión de esta situación, ciertamente novedosa, de un tratado que no quiere serlo. Desde esta perspectiva se parte de cierta negatividad inicial que afecta tanto a la estructura de la obra como a su intención y contenido, marcado originalmente por la interrupción. [...] Es importante mantener la diferencia entre proyecto y parte escrita. [...] El proyecto «Ser y tiempo» solo se encuentra expuesto en la introducción de la obra, un texto que cubre 40 páginas en su versión original" (Leyte, 2005, p. 63). En este orden de ideas, no me refiero al «segundo Heidegger» como lo hacen algunos comentaristas sino a las «obras tardías del autor», pues estas se encuentran en el mismo horizonte de sentido de lo «proyectado» Ser y tiempo.
} 
Se proponen dos claves de interpretación. La primera es observar que los términos «pensar»y «poetizar» pueden asimilarse el uno al otro en cuanto que, en términos de Heidegger, ambos son «aperturidad de lo ente» — los dos son «Decir» die Sage- . No obstante, en cada uno se presenta un modo distinto del decir Sagen -y por ello pueden distinguirse- - La segunda clave de interpretación es poner atención al tipo de «silenciamiento de lo ente» que en cada caso se da. Para apoyar estas ideas se trabajará en un primer momento la lección de 1935 Origen de la obra de arte para comprender lo que significa «aperturidad» $y$, en segundo lugar, se abordará el tipo de silencio que hace el «decir» pensante y el «decir» poético.

\section{La obra de arte como «aperturidad»}

En las obras tardías de Martin Heidegger puede advertirse una dificultad de distinción entre dos aspectos fundamentales de su pensamiento: pensar y poetizar. No resultan muy claras las distinciones que el mismo filósofo establece, por ejemplo: "así y todo, no podemos decidir aquí de manera definitiva si la poesía es, en lo propio, una forma de pensamiento o si el pensamiento es, en lo propio, una forma de poesía" (Heidegger, 2002, p. 140). Es bastante «oscura» la relación entre estos dos modos del decir, más aún cuando el mismo filósofo alemán deja claro que estos dos «vecinos» se encuentran bajo una «luminosa» diferencia. Por ello, surge la pregunta: ¿qué tan clara tiene el mismo Heidegger la diferencia entre pensar y poetizar cuando reconoce una «oscuridad» en la relación, pero afirma una «luminosidad» en la diferencia?

Debemos abdicar de la opinión de que la vecindad entre poesía y pensamiento se agota en la turbia y vociferante amalgama de ambos modos del decir, donde cada uno se apropia de aspectos inciertos del otro. [...] A la poesía y al pensamiento los mantiene separados una delicada, aunque luminosa diferencia, cada uno sostenido en su propia oscuridad [...] [énfasis añadido]. Poesía y pensamiento no están separados si por separación se entiende: relegado a no poder sostener relación alguna. Las paralelas se entrecruzan en el infinito. (Heidegger, 2002, p. 145)

Heidegger no concibe la relación entre pensar y poetizar como si esta se fundara en una cercanía de elementos entre cada una de las partes. Por el contrario, lo que el filósofo quiere poner en evidencia es más bien una cercanía ontológica ${ }^{2}$ con una distinción mutua de corte epistemológico. En efecto, estos

\footnotetext{
${ }^{2}$ La cercanía entre pensar y poetizar se puede entender en términos ontológicos, pues ambos sugieren una unidad que solo encontraría una diferencia en sus modos de manifestarse. Así, la búsqueda de una «diferencia» entre estos dos «modos del decir» sugiere la necesidad de un camino fenomenológico que las distinga.
} 
dos aspectos se pueden abordar ontológicamente como «lo mismo», pero en cada uno se da un modo de proceder que los distingue.

Pensar y poetizar son lo mismo. Sin embargo, dicen cosas distintas en cada caso, o más bien «callan» cosas distintas. A eso se refiere Heidegger cuando afirma que la relación entre pensar y poetizar está sostenida por su propia "oscuridad" (Heidegger, 2002, p. 145). La clave para comprender la diferencia está en atender a eso que «callan» en cada caso el pensar y el poetizar. En definitiva, si hay una distinción entre estos dos «vecinos» — tal y como los Ilama Heidegger — es la advertencia de que en cada caso se «calla» algo distinto.

Para comprender el quehacer de la poesía y el pensamiento con «lo ente», es necesario tomar en consideración lo que significa para Heidegger la obra de arte, pues en ella se da un fenómeno fundamental. El pensador afirma que "la obra como obra instala un mundo. La obra tiene abierto lo abierto del mundo" (Heidegger, 1976, p. 37). El ejemplo clásico de Heidegger en este asunto es el del templo griego, como obra de arte, que se erige en el monte y «funda» un espacio en el que habita «el dios».

La obra-templo, por el contrario, puesto que instala un mundo, no hace desaparecer la materia, sino que es lo primero que la pone de relieve $y$, por cierto, que en lo abierto del mundo de la obra la roca pasa a ser soporte y a descansar y solo así llega a ser roca, los metales llegan a fulgurar y lucir, los colores a iluminar, el sonido a vibrar, la palabra a decir. Todo esto sale a relucir al retirarse la obra a lo macizo y pesado de la piedra, a lo firme y elástico de la madera, a la dureza y brillo del mineral, a la luminosidad y oscuridad del color, a la sonoridad del sonido y a la fuerza y designación de la palabra. (Heidegger, 1979, p. 38)

En el ejemplo del templo griego, Heidegger pone en evidencia aquello que sucede cuando una mera cosa, como la piedra, la madera, el metal, etc., se convierte en un lugar de aperturidad de lo ente, es decir, en el «ente» en el que realmente la cosa puede ser cosa y así es apreciada en todo su «ser». Este concepto, que parece enrevesado en Heidegger, podría comprenderse desde esta situación: el mármol, al estar en los filones de las montañas no es apreciado como mármol hasta que es «elevado» a obra de arte. Solo allí, es posible «ver» el mármol en toda su «cromaticidad». La obra de arte hace posible que las «cosas» no pasen desapercibidas. En definitiva, el arte es el lugar privilegiado en el que lo «ente» puede «aparecer». Se puede afirmar, entonces, siguiendo el orden de ideas de Heidegger sobre la obra de arte que, cuando el artista ha culminado su obra, esta se ha convertido en «fundación de mundo» y por ello no es un objeto en el mundo sino la fundación de un mundo a su alrededor. Así, la obra de arte 
no es más una posesión del artista que la produjo, sino que esta va más allá de su posibilitador. En este sentido, podemos comprender análogamente lo que sucede con el decir poetizante del poeta. El poema es también una fundación de mundo, pues las palabras que se pronuncian en él se hacen nuevas, «dicen» lo ente, lo «muestran».

Por otro lado, cuando el poeta ha proferido sus palabras y ha posibilitado con ellas que sea «dicho» lo ente, este ha renunciado a poseer el carácter de ser-obra (poiesis) de su creación. Ahora debe asumir un papel de espectador de su propia obra, pues ya no la posee. Puede decirse, en definitiva, que el poeta ha hecho silencio en su «decir poético», pues no es él quien cobra el protagonismo, sino lo «mostrado» en sus palabras. No obstante, el silencio del poeta no es simplemente su retraimiento, es más bien lo que posibilita: la «instalación de un mundo» —y no de objetos en el mundo-. Así, el mundo entendido como silencio poetizante sería el trasfondo indecible en donde resplandecen los entes; las palabras en el poema. En efecto, el mundo es la «fundación»que hace el poeta, en el que las palabras pueden pronunciarse en su nueva tonalidad y dan sentido y orientan todo.

El poeta guarda «silencio» en su «hablar», en la «fundación» de lo ente entendamos aquí el decir del poeta como un «canto de lo ente»—. Sin embargo, ¿qué se entiende por silencio? Debemos alejarnos, así como lo hace el mismo Heidegger, de la acepción ordinaria de la palabra «silencio». Veamos la orientación que nos brinda el filósofo alemán.

El asombro o el pavor pueden privar al hombre de habla. Está, entonces, asombrado y consternado. Ya no habla: guarda silencio. Alguien puede perder el habla a causa de un accidente. Ya no habla. Tampoco guarda silencio. Permanece mudo. Para hablar se precisa de la articulación de sonidos, sea que la efectuemos — en el hablar; sea que nos abstengamos de ella- guardando silencio; o bien sea que seamos capaces de ello enmudeciendo. (Heidegger, 2002, p. 181)

Cuando se dice que el poeta «guarda silencio», no se hace referencia a un simple callar, a un enmudecer. El poeta guarda silencio precisamente porque tiene mucho que decir. En efecto, ese silencio - que no es en modo alguno una ausencia- es el que hace posible que las palabras digan, hablen, suenen. No 
obstante, el medio privilegiado del quehacer del poeta es la escritura ipuede darse en la escritura un silenciamiento poético que permita un «nuevo decir»? Pensemos ahora si la escritura puede ser un medio que privilegie ese tipo de silencio en el que prevalece el «decir poetizante».

La escritura, desde la antigüedad, es percibida a menudo como un «mal menor $\rangle^{3}$. Así, permitiendo la transmisión de conocimientos a las generaciones futuras se convierte en el «documento» que sedimenta el pensamiento filosófico; lo reduce a letra fija, inmóvil. En consecuencia, lo que en un principio solo podía hacerse por medio de la viva voce — como Sócrates al hacer filosofía en el discurso, en sus preguntas, en la dinámica del diálogo_-, debió ser puesto por escrito, pues sus discípulos no querían que se perdiera el legado de la filosofía socrática. Aunque Platón escogió el "diálogo" como modo de escritura para salvaguardar la naturaleza del discurso socrático, sucedió que el dinamismo de las conversaciones de Sócrates se expuso al riesgo de terminar diluido en la letra. En efecto, algo de la experiencia original termina por perderse; una dimensión de la filosofía se silencia: el dinamismo que el pensamiento tiene en el discurso hablado.

En la escritura se da un tipo de silenciamiento. Pues mientras un texto no sea leído, mientras no entre en «diálogo» con el lector, permanece como letra muerta. Sin embargo, la escritura ha hecho posible que las palabras del poeta se «actualicen» en boca de otros. En este sentido, se replica el «efecto» que tienen las palabras dichas poéticamente: «ponen a pensar», «llaman al pensamiento». Es necesario hacer explícito que dentro de los múltiples sentidos de la palabra «silencio» solo se tiene interés por dos acepciones, porque son las que están en juego en las consideraciones que hace Heidegger en torno al pensar y al poetizar.

\footnotetext{
${ }^{3}$ En los Seminarios de Zollikon, Heidegger cuenta una anécolota sobre un sofista que reprochaba a Sócrates el haberse dedicado, después de mucho tiempo, a decir siempre «lo mismo». Sin embargo, Sócrates desconcierta cuando responde de modo paradójico a la acusación. Veamos el texto de la anécdota: "Un sofista que había viajado mucho le pregunta a Sócrates: «¿Estás todavía aquí y sigues diciendo lo mismo? Pero así te pones la cosa fácil». Sócrates responde: «No, ustedes, sofistas se la ponen fácil, pues dicen siempre las novedades y lo más nuevo y cada vez algo diferente. Pero lo difícil es decir lo mismo y lo más difícil: decir lo mismo de lo mismo»" (Heidegger, 2013, p. 55). Esta anécdota presenta la oposición entre dos comprensiones del quehacer filosófico. Por un lado, el sofista representa una filosofía que quiere estar siempre en la vanguardia y por otro, Sócrates personifica el tipo de filosofía que se esfuerza por conservar vigente un misterio: «lo mismo». La filosofía como texto escrito tiene una idea implícita, la necesidad de avanzar, de desarrollar un «tema» nuevo cada vez. Por el contrario, la filosofía como diálogo puede mantenerse en «lo mismo de lo mismo», el discurso lo permite, Sócrates lo personifica.
} 
Estas dos acepciones son: 1) el silencio se aparta de todo proceder objetualizador ${ }^{4}$ —al modo de la ciencia - para permitir el camino hacia el pensar y 2) el silencio es la invocación del pensamiento que dispone a quien quiere seguir por las sendas del pensar.

\section{El «silenciamiento» de lo ente}

La primera acepción que se propone retoma la consideración heideggeriana de asumir que para poder dirigirnos hacia el pensar, es necesario el abandono de la ciencia, pues esta, en su proceder objetualizador se encuentra en una situación muy particular con respecto al pensar; "la ciencia [...] no piensa" (Heidegger, 2010, p. 19). Así, el profesor de Friburgo comprende que el pensamiento

\footnotetext{
4 Para comprender lo que significa «proceder objetualizador» tomaré una cita de Heidegger en Conferencias y artículos traducida por Eustaquio Barjau. La afirmación original reza: "Wir nennen jetzt die Art der Anwesenheit des Anwesenden, das in der Neuzeit als Gegenstand erscheint, die Gegenständigkeit" [énfasis añadido], Barjau la traduce así: "Llamaremos ahora al modo de presencia de lo presente que aparece en la época moderna como objeto la obstancia" [énfasis añadido] (Heidegger, 1994, p. 48). La palabra alemana Gegenständigkeit al final de la frase original es traducida como "obstancia". Hagamos una reconstrucción de la palabra Gegenständigkeit. En un primer momento, Gegenstand traduce «objeto»; sin embargo, Gegenstand está compuesto por Gegen que significa «contra» y stand, «estar de pie». Parece entonces que tenemos algo que tiene la condición de ser opuesto a una cosa y que se erige frente a ella. Sin embargo, al ver la raíz latina de objeto, objectum, podemos también ver cómo ob-jectum está compuesto a su vez por la partícula ob que significa «frente» y jectum que traduce «lanzado» (al modo de una in-yección). La palabra «obstancia» que en el castellano ha caído en desuso y en el alemán no tiene correlato, ha sido usada por el traductor Barjau para traducir Gegenständigkeit. Es posible que el traductor haya tomado la primera parte de objectum y el final de Gegenstand (ob-stancia) para mantener la raíz alemana de Gegenstand en su carácter de estar opuesto a algo y de objectum como lo que está en frente. No obstante, la palabra "obstancia" sigue resultando problemática. El vocablo Gegenstand (objeto), afirma Heidegger, "surge por primera vez en el siglo XVIII, concretamente como traducción alemana del «objectum» latino" (Heidegger, 1994, p. 47); Gegenstand es "objeto" en el alemán, como traducción de objectum. No obstante, llevar al español el sentido de Gegenständigkeit por medio de la fragmentación de dos palabras de dos idiomas distintos y produciendo algo que en el alemán no tiene traducción resulta más difícil que decir sencillamente, en este caso y para facilitar la comprensión, objetualidad en lugar de obstancia. Veamos cómo se llega progresivamente a la palabra que proponemos. Inicialmente Gegenständig traduce "opuesto" y Gegenstand "objeto". Heidegger toma estas dos palabras alemanas y añade la terminación keit, es decir, lo que tiene la «condición de». La palabra Gegenständigkeit es entonces aquello que tiene la condición de erigirse frente a algo como opuesto. Aquí en la conferencia Ciencia y meditación, se trata de la comprensión moderna de objeto. Objetualidad sería finalmente el modo moderno de comprender "la presencia de lo presente (Heidegger, 1994, p. 48). es decir, objetualidad es la diferencia que la época moderna marca con el representar de lo presente como objeto en el pensar griego y medieval (p. 47). Por esta razón, podemos leer objetualidad como traducción de Gegenständigkeit. Para fortalecer nuestra decisión, podemos también tener presente que el término Gegenständigkeit es traducido al inglés en el diccionario histórico Heidegger's Philosophy como objectness (Schalow \& Dennker, 2010, p. 340). La traducción que hace Dahlstrom en The Heidegger Dictionary de Gegenständigkeit es Objectivity y afirma que objetividad en este caso se presenta como representación de «sujeto» que en esta ocasión no resulta ser nada contingente sino el sujeto en general; "The subject here is not any contingent, individual subject but a rational subjectivity that countenances only what can be the object of inference and calcualtion" (Dahlstrom, 2013, p. 145).
} 
debe ser invocado; llamado ${ }^{5}$ (heißen). Como consecuencia de lo que entiende Heidegger por «pensamiento», se hace necesario el abandono de la ciencia que solo está en relación con los entes- para dar paso al pensamiento. Así, se comprende la necesidad de entender el silencio pensante como una «invocación del pensamiento».

Para Heidegger el pensar está en una íntima relación con el poetizar y no será posible encontrar una diferencia entre los dos si no se dirige la atención hacia las fuentes del pensamiento y la poesía. En efecto, vistos desde lejos, el pensamiento y la poesía tienen su origen en la misma fuente; los dos son modos privilegiados del «decir» y ambos tienen el anhelo de mostrar «ser». Sin embargo, Heidegger comprende el decir así: "decir significa: mostrar, dejar aparecer; ofrecimiento de mundo en un claro que al mismo tiempo es ocultación -ambos unidos como libredonación" Heidegger, 2002, p. 159). Si pensamiento y poesía son dos modos del «decir» entonces podría decirse que en cierto sentido son lo mismo; son «claros de lo ente». No obstante, si en cada caso se da un «modo» diferente es porque se sugiere una distinción entre poesía y pensamiento. Atendamos primero a lo que significa ese «claro» que para el pensador alemán es la vía de acceso hacia «ser». Para apoyar esta idea, se propone una imagen del mismo Heidegger.

Cuando Heidegger habla de «claro» se puede pensar en los espacios vacíos que las ramas de los árboles de los bosques permiten; en estos sucede que posibilita el paso de la luz del sol porque «abren» un camino. A estos espacios podríamos llamarles, de manera análoga, «claros de bosque» o «claros de lo ente». Así, lo que Ilama la atención es que en ellos se puede reconocer una «aperturidad»que, en cierto modo hace posible el paso de la luz porque la aperturidad está constituida por lo ausente. En este caso, lo importante es lo que no está, pues hace posible el «aparecer» de lo ente. ¿Puede esta imagen permitirnos comprender lo que hace la poesía y el pensamiento? Juntos, poesía y pensamiento son «claros» en donde lo ente hace su aparición. Sin embargo, son distintos en cuanto que el pensar es un «advenimiento»y la poesía un «acaecimiento».

El pensamiento es un advenimiento porque solo será posible cuando se halla abandonado el proceder objetualizador de la ciencia y se haga posible así el acaecimiento de «lo nuevo», lo que la poesía tiene por decir. En cambio, el «acaecimiento» ${ }^{6}$ de la poesía sugiere algo distinto, puede vincularse directamente con la comprensión que tiene Heidegger del «ser obra» de la obra de arte en su conferencia del año 1935, Origen de la obra de arte. En efecto, para el pensador

\footnotetext{
${ }^{5}$ De esta manera, ¿heißen en la pregunta Was heißt Denken? podría ser traducido, atendiendo a su múltiple significación como "iqué es lo que nos orienta hacia el pensar, lo que nos llama a pensar?" (Heidegger, 2010, p. 119; Ortega, 2016, p. 22).

6 Aunque la palabra «acaecimiento» significa ordinariamente "cosa que sucede" (Real Academia Española, 2001, $22^{\circ}$ ed.), en este contexto queremos entenderlo como «acontecimiento fundador». Es decir, como la poesía en la que acaece el mundo.
} 
alemán la obra de arte "abre un mundo y al mismo tiempo lo vuelve a situar sobre la tierra, que solo a partir de ese momento aparece como suelo natal" (Heidegger, 2014a, p. 30). La poesía también funda una comprensión del mundo que, siguiendo a Gadamer, se configura para nosotros como historia transmitida en el lenguaje (Grondin, 2003, p. 42). Así, el acaecimiento de la poesía extrae la oscuridad al mundo que le circunda y permite que «lo ente» aparezca en su «ser». En consecuencia, el pensamiento para Heidegger no es posible si no está en tradición, es decir, no puede ser concebido como un comienzo desde cero, sino como una continuación, un «diálogo» con la tradición. En palabras de Heidegger, "solo podemos sobreponernos a lo pensado de un pensador haciendo que lo no pensado en lo pensado por él sea llevado a su verdad inicial" (Heidegger, 2010, p. 45).

Pensar en tradición no significa la simple repetición de lo dicho en el pasado. Esto encierra un peligro que Heidegger pone en evidencia cuando cita una línea del Zaratustra de Nietzsche: "«todos hablan de mí, pero nadie piensa en mí»" (Heidegger, 2010, p. 43). Ciertamente, cualquier pensamiento puede convertirse en objeto de habladurías que impiden el diálogo con los autores de la tradición. Así, la tentación de repetir lo que un filósofo ha dicho puede entorpecer la posibilidad de que el pensamiento «aparezca»; también para el pensar se hace necesario un tipo de silenciamiento que libere de las habladurías, incluso de las escribidurías. En efecto, Nietzsche es un pensador que utilizó aforismos para transmitir sus ideas. El riesgo de su estilo es la sensación que queda de querer repetirlo una y otra vez. Sin embargo, quienes siguen ese camino "simplemente se embriagan con trozos y frases y a ciegas se tambalean de aquí para allá en su lenguaje, en lugar de tomar el camino del pensamiento" (Heidegger, 2010, p. 40). ¿Cómo evitar el fracaso del pensamiento en la anulación de sentido que trae la repetición irreflexiva? Heidegger propone que se tome el camino del pensamiento. ¿Qué quiere decir Heidegger con "tomar el camino del pensamiento" (p. 40)? Nos ponemos en camino hacia el pensamiento cuando se da lugar al «silencio» que permite realmente el «escuchar». En definitiva, pensar es una actividad muy silenciosa que obliga a «prestar oídos» al rastro que dejan los pensamientos de los filósofos de la tradición. Ciertamente, hay una cercanía entre el decir poético y el decir pensante. En palabras de Heidegger.

Poesía y pensamiento, sin embargo, son modos del decir, aún más, son modos eminentes. Si los modos del decir deben ser vecinales desde su proximidad, entonces la proximidad misma debe prevalecer por el modo del Decir. La proximidad y el Decir serían entonces lo mismo. (Heidegger, 2002, p. 149)

En este fragmento Heidegger afirma que hay un «Decir» — que nombra como la proximidad entre la poesía y el pensamiento- y dos modos eminentes de ese decir, a saber: poesía y pensamiento. En efecto, poesía y pensamiento hacen 
lo mismo: «Dicen». No obstante, hay una diferencia en cada caso, porque se da un modo de decir distinto. Nótese que en la cita Heidegger pone la palabra «Decir» con mayúscula. Sin duda, Heidegger quiere hacer evidente una diferencia entre «Decir» (con mayúscula) y «decir» con minúscula. En el primer caso, el filósofo escribe «Decir» utilizando la palabra die Sage (el decir) y cuando la escribe con minúscula utiliza Sagen (decir); "la palabra die Sage, Decir. Significa el decir, lo que el decir dice y lo que está por decir" (Heidegger, 2002, p. 109). Por lo anterior, se podría decir que Sagen es la mostración del pensamiento que conduce hacia "lo que el decir dice y [está] por decir" (p. 109). De modo que el pensamiento se convierte en medio y camino para que el lenguaje nos muestre su epifanía. Pero iqué significa este «decir» del pensamiento?" "presumiblemente lo mismo que mostrar en el sentido de: dejar aparecer y dejar relucir, pero en el modo de «señalar»" (Heidegger, 2002, p. 109). En definitiva, en la poesía hay un «acaecimiento», pero guarda relación con lo que el pensamiento trae; hay una vecindad entre las «mostraciones» del pensamiento y la poesía.

Hasta ahora se ha intentado dimensionar el horizonte de la diferencia y proximidad entre la poesía y el pensamiento en dos modos de silenciamiento de lo ente: cada uno propicia un silencio distinto. En el caso del pensamiento, este propicia un silencio de «advenimiento» de la «verdad» y en el de la poesía, el silencio se convierte en un «acaecimiento» de la «verdad». Es necesario abordar ahora la cercanía entre die Sage y Sagen pues esto da cuenta de la cercanía entre pensar y poetizar y poder comprender lo que significa en la poesía «acaece la verdad».

Vecindad significa: morar en la proximidad. Poesía y pensamiento son
modos del decir. Ahora, a la proximidad que conduce poesía y pensamiento
a su mutua vecindad, la llamamos die Sage, el Decir. Suponemos que en él
reside la esencia del habla. Sagen, sagan, significa mostrar: dejar a parecer;
liberación luminosa-ocultadora, entendida como ofrecimiento (lichtend-
verbergend frei-geben als dar reichen...) de lo que llamamos mundo. El
luminoso-velador enmascarante ofrecimiento del mundo es la naturaleza
esencial del decir. (Heidegger, 2002, p. 148)

En este apartado Heidegger da una pista para comprender la proximidad y la lejanía entre pensar y poetizar. En efecto, pensar y poetizar se encuentran en

\footnotetext{
El pasaje completo se encuentra en el contexto de un diálogo entre un japonés y un inquiridor, publicado en Unterwegs zur Sprache. Cito a continuación el pasaje en el original: "F Das Wort »die Sage«. Es meint: das Sagen und sein Gesagtes und das zu-Sagende. J Was heißt sagen? F Vermutlich das Selbe wie zeigen im Sinne von: erscheinenund scheinenlassen, dies jedoch inder Weise des Winkens" (Heidegger, 1959, p. 137). Claramente hay un modo de «mostración» que obedece a la necesidad del pensar de un decir no objetualizador. Por ejemplo, en la Carta sobre el humanismo Heidegger afirma que "el pensar tiene que llegar a decir el ser en su verdad, en lugar de explicarlo como un ente a partir de lo ente, tendrá que quedar abierta y al cuidado del pensar la cuestión de si acaso y cómo el ser es" (Heidegger, 2014b, p. 275). En este sentido lo que el Decir hace es una señal o un guiño [Winkens].
} 
la cercanía de la «vecindad» en cuanto que ambos son dos modos privilegiados del «Decir». Pero se distancian en cuanto que también son Sagen (decir) esto es, mostración, aparición, y cada uno lo hace desde su particularidad. Así, nadie puede confundir el lenguaje de la poesía con ningún otro. Un estadista no puede comunicar el resultado de sus investigaciones con un lenguaje poético, tampoco un funcionario público o un militar cuando da una orden. Sabemos que la poesía es un Sagen que tiene un modo de manifestarse claramente identificado en la sociedad. Así, la poesía tiene un modo (Sagen) muy particular del Decir (die Sage).

El pensamiento no es tan fácilmente identificable como sí lo es la poesía. Pues el decir (Sagen) del pensar es más bien un «llamado» que «pone a pensar». Heidegger pone un ejemplo muy vívido en la quinta conferencia que pronunció en la Universidad de Friburgo en el semestre de invierno de 1951. "¿Qué significa pensar? Guardémonos del afán que para esta pregunta quisiera obtener una respuesta en forma de una fórmula. Ciñámonos a la pregunta. Atendámonos a la manera en que ella pregunta. «¿Qué significa pensar?»" (Heidegger, 2010, p. 38).

«!Espera niño!, te voy a enseñar lo que significa obedecer», exclama la madre ante su hijo que no quiere volver a casa. ¿Promete la madre a su hijo una definición sobre la obediencia? No. ¿O quizá le da una lección? Tampoco, supuesto que sea una madre como Dios manda. Más bien ella enseñará al niño a obedecer. O mejor dicho, a la inversa, llevará al niño a la obediencia. Y conseguirá eso cuanto más eficazmente, cuanto menos veces toque la campanilla. Lo conseguirá tanto más sencillamente, cuanto la madre lleve de manera más inmediata al niño a escuchar [énfasis añadido]. Y no lo hará por el hecho de simplificar el trabajo, sino porque el hijo ya no puede dejar de escuchar. ¿Por qué no? Porque él se ha hecho oyente de aquello a lo que pertenece su esencia. (p. 38)

A partir de la imagen de la madre que propone Heidegger, el pensamiento tiene la labor de educar los oídos de quien debe ponerse en camino hacia el pensar. Es por eso que el «decir» (Sagen) del pensamiento tiene la labor de «conducir» —y en este sentido es un «advenimiento»—, más que de comunicar un contenido ${ }^{8}$. En definitiva, el pensamiento dispone, prepara y conduce hacia la epifanía del pensar — hacia el «acontecimiento» del pensar-, pues "nos adentramos en lo

\footnotetext{
${ }^{8}$ La poesía y el pensamiento se mueven en una vecindad que las acerca en un Decir originario (entendido como die Sage) y las diferencia en dos modos eminentes del decir (entendido como Sagen). Así, tanto en el pensamiento como en la poesía hay «silenciamiento» de lo ente. En este sentido, en la poesía hay más un oír que un decir. En efecto, "hacer poesía, dichten, significa: re-decir (nach-sagen), esto es, decir de nuevo la eufonía pronunciada por el espíritu del Retraimiento. Antes de ser un decir en el sentido de la afirmación, hacer poesía es, durante la mayor parte del tiempo, un oír" (Heidegger, 2002 , p. 54). Solo después de haber medido el silencio en toda su extensión sabremos lo que nos es permitido decir (p. 22).
} 
que significa pensar cuando pensamos nosotros mismos" (Heidegger, 2010, p. 15).

A manera de conclusión se puede afirmar que hay una cercanía entre el decir poético y el decir pensante: son «Decir»y, en ese sentido, ambos tienen el anhelo de mostrar «Ser». Sin embargo, cada uno es un «modo» distinto de «Decir». Por ello se estableció una relación entre los dos modos del «Decir» en cuestión con el silencio que en cada caso se realiza. Por un lado, está el silencio pensante que busca apartar el proceder de la ciencia — que solo trata con los entes- del horizonte del pensar y, por otro, el silencio poetizante, que es invocador del pensamiento. En este sentido, la clave para entender esa diferencia entre pensar y poetizar, que no es para nada evidente en la obra del autor alemán, está en el «silencio» que se hace en cada caso: el silencio del «pensar» como un «advenimiento» y el silencio de la poesía como un «acaecimiento» de lo ente en las palabras del poeta.

\section{Referencias}

Dahlstrom, D. O. (2013). The Heidegger Dictionary. Bloomsbury Academic.

Grondin, J. (2003). Introducción a Gadamer. (C. Ruiz-Garrido, trad.). Herder.

Heidegger, M. (1959). Unterwegs zur Sprache. Vittorio Klostermann.

Heidegger, M. (1979). Sendas perdidas Holzwege (3ra ed.). Losada.

Heidegger, M. (1994). Conferencias y artículos. (E. Barjau, trad.). Odós.

Heidegger, M. (2002). De camino al habla (I. Zimmermann, trad.). Serbal.

Heidegger, M. (2010). ¿Qué significa pensar? (R. Gabás, trad.). Trotta.

Heidegger, M. (2013). Seminarios de Zollikon (Á. Xolocotzi Yáñez, trad.). Editorial Herder.

Heidegger, M. (2014a). Caminos de bosque. Alianza Editorial.

Heidegger, M. (2014b). Carta sobre el humanismo. (Helena, C \& A. Leyte, trads.). Alianza Editorial.

Heidegger, M. (2015). Cuadernos negros. En P. Tracuny. (Ed.). Editorial Trotta. 
Leyte, A. (2005). Heidegger. Alianza Editorial.

Ortega, O. (2016). ¿Qué significa pensar? El seguimiento de un camino hacia el pensar en Martin Heidegger [Tesis de pregrado] Pontificia Universidad Javeriana, Bogotá, Colombia. https://repository.javeriana. edu.co/bitstream/handle/10554/18932/OrtegaChaconOrlando2016. pdf? sequence $=1$ \&isAllowed $=y$

Schalow, F. \& Dennker, A. (2010). Historical Dictionary of Heidegger's Philosophy. The Scarecrow Press. 